\title{
Exploring Smartphone Users' Social Information Behavior
}

\author{
I-Ping Chiang \\ Graduate Institute of Information Management, National Taipei University, \\ Email: ipchiang@mail.ntpu.edu.tw \\ Jie-Yun Yang \\ Graduate Institute of Information Management, National Taipei University, \\ Email: syyang26@gmail.com \\ Yi-Jou Wu \\ Graduate Institute of Information Management, National Taipei University, \\ Email: zoe839923@gmail.com
}

\begin{abstract}
As the popularity of social network services (SNS) grows, users' online behavior is increasingly being affected by SNS browsing. Now, mobile device serve as a tool for social connection, provides an increasingly important communication channel in facilitating social connections. SNSs that are adequate for mobile devices have been developed. To clarify web user social information behavior, this study used social network sites to analyze smartphone user online behavior by collecting user clickstream data over a period of 3 months. The influence of SNS browsing on types of external sites visited-namely news, shopping, searches, forums, videos, and blogs-is examined. This study used a site-centric approach, wherein user data was examined by using association rules and the Jaccard Index to explore the relationship between SNS and other online activities. We collaborates with InsightXplorer to recruit smart phone users, collected 580 samples from the consumers who use the smartphone. First, usercentric approach will be conducted for correlation analysis to quantify the association between SNSs and other categories, and then use the results as the standard to conduct fixed effect model by exploring the duration of gender, age and weekdays/weekend at 24hrs. Second, site-centric approach will conduct correspondence analysis and association rules by using users' session to gather all categories in the graph and explore the relationship between the SNSs and the other categories. The result shows that Taiwanese smartphone users use Facebook (both Web and App) as a news-seeking,
\end{abstract}


topic-seeking, video-seeking and word-of-mouth-seeking platform. That means Facebook will become a portal. When people want to find something interesting, the first thing is to open Facebook and searching their timeline. Finally, based on the findings, this study to provide a stepping stone for marketers and researchers to understand web users' social information behavior.

Keywords: Smartphone, Social information behavior, Web usage mining, Clickstream data, Mobile commerce

\section{INTRODUCTION}

Since the rise of smartphones, numerous studies have investigated online information behavior. In recent years, the impact of the online community has continued to rise, and the use of social networking services is already one of the main behaviors of Internet users. Google and Ipsos MediaCT interviewed 1,000 Taiwan Please check the wording.se smartphone users aged 18-64 in 2013 and reported that 93\% visited social networking sites and that $61 \%$ visited the sites daily. In 2015, Foreseeing Innovative New Digiservices (2015) reported that use of social networking sites was the third most common online behavior. Studies have also examined the type of information (e.g., news and shopping) collected on smartphones. For example, in 2015, the Knight Foundation commissioned Nielsen to survey how people used smartphones to access news information. The results demonstrated that people used social networking apps such as Facebook, Twitter, and Google+ to access news-most notably entertainment news. Bronto (2015) reported that more men both browsed and purchased products from online shopping sites than do women. Numerous studies support the theory that social network sites affect smartphone user information behavior. "We Are Social and Hootsuite" recently published the Digital in 2017 Global Overview report, which reveals that more than half of the world's population now uses the internet. This report identified a wealth of other important milestones. Almost two-thirds of the world's population now has a mobile phone. More than half of the world's web traffic now comes from mobile phones. Most of the past literature discusses some privacy and security issues using social networking sites, and less literature discusses the use behavior between social networking sites and mobile devices.

Information behavior is changing as smartphones become increasingly pervasive, allowing for more access to information. This study used web usage mining to explore user smartphone clickstream data in order to reveal information behavior patterns. In this paper, we clarify the following research question: Which of the following 
categories - news, shopping, forums, videos, and blogs — have relationships with the social network sites (SNS)?

\section{LITERATURE REVIEW}

\section{Mobile SNS}

The increased use of the Internet as a new tool in communication has changed the way people interact. According to traditional social network theory, a social network refers to the aggregation of people who are connected socially through close acquaintances, information sharing, and etc. (Garton et al., 1997). Today's social network theory focuses on online or Internet activities (Kwon \& Wen, 2010; Nikou \& Bouwman, 2014).

Raacke and Bonds-Raacke (2008) discussed in light of the impact that friendnetworking sites have on communication and social needs of college students. Now, cell phones serve as a tool for social connection, provides an increasingly important communication channel in facilitating social connections. SNSs that are adequate for mobile devices have been developed. However, mobile SNSs differ from the Internetbased sites because mobile SNS users are provided with the mobility to use services anytime and anywhere (Zhou et al., 2010). Consequently, mobile SNSs are deemed to include all of the following attributes: (1) attributes of social networks, (2) attributes of the internet, and (3) attributes of mobility.

Most of the research on mobile telephony has explored the effects of mobile phone calls and texts on maintaining pre-existing social connections (Ito, Okabe, \& Matsuda, 2005; Katz, Katz, \& Aakhus, 2002; Ling, 2004). Looney, Jessup, and Valacich (2004) claimed that the capability of communicating from anywhere at any time offers extraordinary flexibility and convenience, which can affect behavioral intentions.

Moreover, Ha, Kim, Libaque-Saenz, Chang, \& Park (2015) founded on the theory of uses and gratifications, this research attempts to identify gratifications driving mobile SNSs use. The results shed light on social interactive gratification and mobile convenience had an impact on all other gratifications. Chen, Hsu, \& Lu (2018) study impact of flow on mobile shopping intention, understanding how flow mediates consumers' mobile shopping intention can help online companies to formulate effective marketing strategies. Theoretical implications and suggestions for future research are provided.

\section{Information Behavior and Social Information Behavior}

Wilson (1999) propose that a user may feel “demand” and may accordingly exhibit different patterns of information-seeking behavior. These patterns involve some uncertainties that could result in a wider range of information search behaviors, in order 
to "meet the needs", for example personality, environmental or emotional factors, etc. So Wilson (2000) further conceived the following three terms: information behavior, information-seeking behavior, and information-searching behavior. Pettigrew, Fidel, and Bruce (2001) later proposed the name "online information behavior," which has since been the focus of substantial scholarly attention. Information behavior is the currently the preferred term to describe the many ways in which people interact with information (Bates, 2010). Broder (2002) identified three purposes of user in the informationsearching activities: navigational, information, transactional. Due to the development of social network site, many information behavior studies focused on information sharing. Rioux (2005) indicated that information can be shared through being given by one person and received by others, information sharing cannot be completed by individual alone. At least by two or more participants to participate in the information sharing activities, so all the information sharing activities are occurring in the network. This study focused on information behavior pertaining to social network sites and examined information-seeking and information-searching activities during social network browsing time. We define this behavior as "social information behavior."

Sellen, Murphy, and Shaw (2002) studied mobile information behavior and revealed that mobile users avoid complicated tasks such as information gathering because of the tediousness of opening multiple browsers and typing long pieces of text on mobile devices. Jones, Buchanan, Cheng, and Jain (2006) noted that internet-enabled handheld mobile devices allowed users to fulfill their information needs even while they are away from their offices and homes, but with a mobile device information needs, in theory, can be fulfilled anywhere and anytime.

\section{Web Usage Mining}

Etzioni (1996) first proposed Mining Web mining, which is application of data processing techniques that discover usage patterns of users from the available web data. In order to extract useful information from user access patterns in web documents and services, Cooley, Mobasher, and Srivastava (1997) classified Web mining into Web content mining and Web usage mining. Then, in 2000, Kosala and Blockeel proposed a third type of web mining-web structure mining-—which is based on network structures as shown in Fig. 1. 


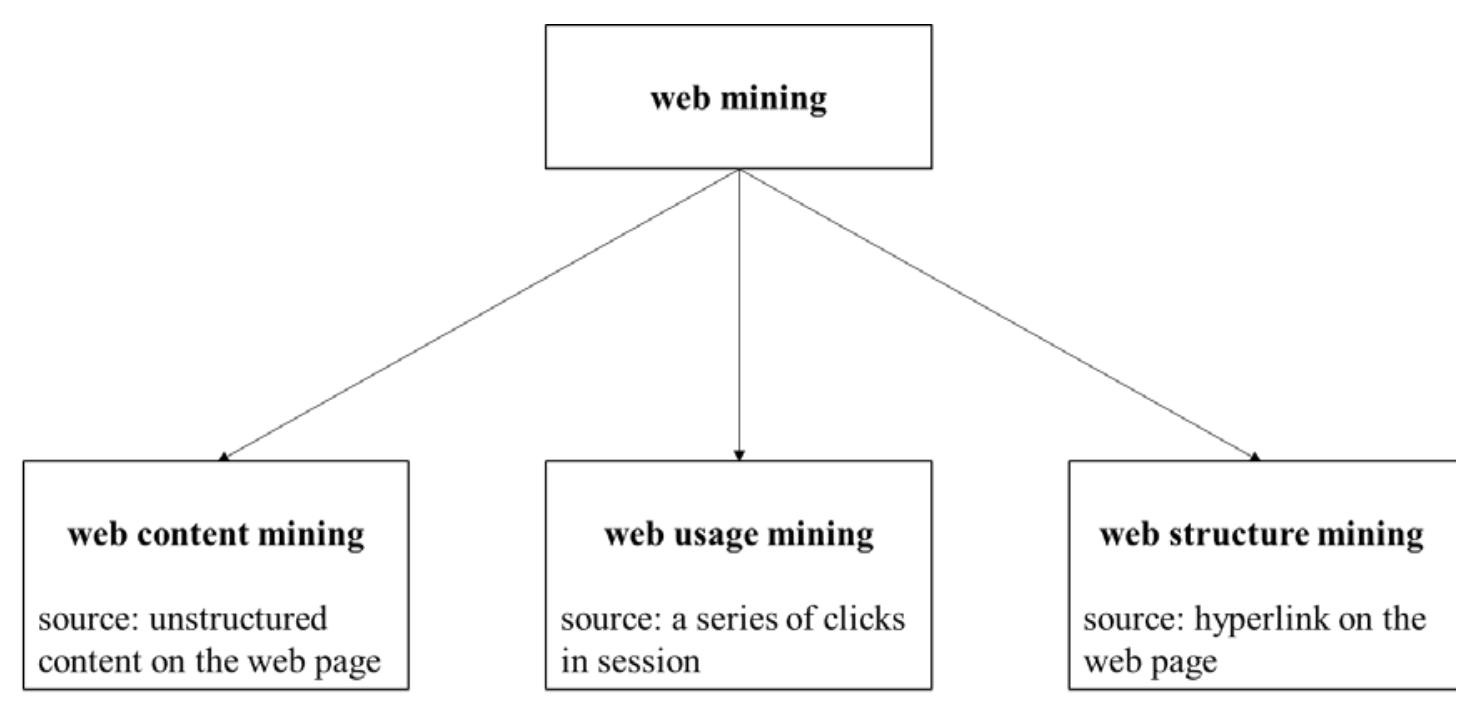

Fig. 1. Three types of mining (Cooley et al., 1997; Kosala \& Blockeel, 2000)

Web usage mining typically involves using clickstream data to explore and analyze patterns automatically. The Clickstream data refers to the record of user clicks between web pages. Clickstream data, first applied by Huberman, Pirolli, Pitkow, and Lukose (1998), uses to observe the data distribution of different web visitors to access the web page. Chou, Li, Chen, and Wu (2010) indicated that collecting clickstream data for web usage mining research can help us find more accurate information from user browsing behavior. Web log files, also considered user clickstream data (Cooley, Mobasher, \& Srivastava, 1999), are commonly used in web usage mining. Cooley et al. (1999) proposed a comprehensive approach, which comprises five difference tasks, including data cleaning, user identification, session identification, path completion, and formatting. In this study, these data pre-processing step is applied to processing web log files.

\section{Web Usage Mining Application}

Web log files record user clickstream data; hence, they are used for analysis in web usage mining because the log files contain user click records. Bucklin and Sismeiro (2009) integrated previous academic studies of clickstream data and focused on two types of clickstream data: user-centric and site-centric. User-centric focuses on understanding user's cross-site activity records, but the samples in a single site might be inadequate. Site-centric pertains to user browsing behavior at a particular website, but not necessarily to user's background information. This study focused on site-centric data.

Church and Smyth (2009) noted differences between information needs associated with mobile searches and those associated with desktop searches. They attributed the differences to the fact that mobile users were on the move and to their interest in locating 
different types of content. In log studies, Halvey, Keane, and Smyth (2006) demonstrated that accesses to particular categories of pages when using mobile phones vary relative to time (weekend and leisure time vs. weekdays and work time). Cui and Roto (2008) used log files and contextual inquiries to identify three categories of information-seeking behavior on mobiles. Nicholas, Clark, Rowlands, and Jamali (2013) used Europeana log files to explain information-seeking behavior on personal computers and different brands of mobile devices.

\section{METHODOLOGY DATASETS}

According to the literature review, the research of information behavior usually uses clickstream data, and the source of clickstream data can be divided into two aspects - "User-centric" and "Site-centric". This study uses the social networking site as a basis to explore the use. In the information behavior of smart phones, the user collects 3 months of clickstream data, and divides each user and session data. In the User-centric aspect, the community is used as the main axis to establish the relationship with each community. The relevant categories then use the fixed effect model to explore the effect of the 24-hour gender age week/end on page views. In the case of Site-centric, the corresponding analysis is used to understand the concept of relative distribution between sites and categories, and then the association rules are used to analyze the probability of simultaneous occurrence of the community and each category.

\section{Association Rules}

Agrawal and Srikant (1994) proposed association rules to describe a method for uncovering relationships between data in large databases. To select interesting rules from all possible rules, criteria such as minimum thresholds on support (i.e., how frequently the rules appeared in the database; Formula 1 and confidence (i.e., how often the rules were found to be true; Formula 2) were considered. In 1997, Berry and Linoff (1997) proposed another criteria-lift; the lift rule is the ratio of the observed support to that expected if $\mathrm{X}$ and $\mathrm{Y}$ were independent (Formula 3). If the lift was $>1$, the degree to which those two occurrences are dependent on one another was measurable can be determined, making lift a useful prediction tool.

$$
\begin{aligned}
& \operatorname{Support}(\mathrm{A} \rightarrow \mathrm{B})=\mathrm{P}(\mathrm{A} \cup \mathrm{B}) \cdot \bullet \cdot \cdot \cdot \cdot \cdot \cdot \cdot \cdot \text {. Formula } 1 \\
& \text { Confidence }(\mathrm{A} \rightarrow \mathrm{B})=\mathrm{P}(\mathrm{B} \mid \mathrm{A}) \cdot \bullet \cdot \bullet \cdot \bullet \cdot \bullet \cdot \bullet \cdot \text { Formula } 2 \\
& \operatorname{Lift}(\mathrm{A} \rightarrow \mathrm{B})=\frac{\mathrm{P}(\mathrm{A} \cap \mathrm{B})}{\mathrm{P}(\mathrm{A}) \mathrm{P}(\mathrm{B})} \cdot \cdot \cdot \cdot \cdot \cdot \cdot \cdot \cdot \cdot \cdot \cdot \cdot \cdot \text { Formula } 3
\end{aligned}
$$

\section{Jaccard Index}

The Jaccard Index is often used to compare the similarity, dissimilarity, and distance of data sets. It measures similarity between finite sample sets and is defined as 
the size of the intersection set divided by the size of the union of the sample sets (Formula 4).

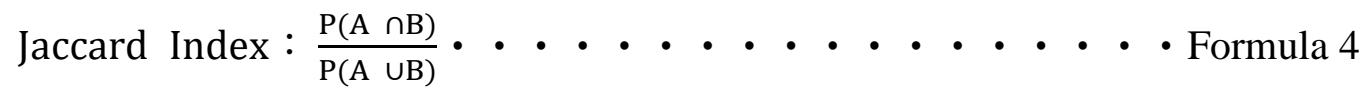

\section{Dataset}

In this study, we cooperated with and collected data from InsightXplorer Limited, Taiwan, which maintains an online panel for Taiwan's cyber market and tracks panelists' online smartphone clickstream data. When clients agree to join the smartphone panel, an app is installed on their smartphones and their clickstream data is automatically sent to our database.

\section{Scope of Data}

This study selected six categories: SNS, news, shopping, forums, videos, and blogs. Websites and apps to be examined were based on InsightXplorer's report on the top 100 sites. The members of the categories "Web" and "App" are listed in Table 1. "Web" here refers to data obtained from browsers (in contrast to that obtained from applications).

Table 1. The Target of Categories and Sites

\begin{tabular}{|c|c|c|c|}
\hline Categories & Sites name & Web name & App name \\
\hline SNS & Facebook & http://www.facebook.com/ & facebook \\
\hline \multirow{5}{*}{ New } & China Times & http://www.chinatimes.com/ & chinatimes \\
\hline & Liberty Times Net & http://www.ltn.com.tw/ & $\operatorname{ltn}$ \\
\hline & udnnews & http://udn.com/ & udn \\
\hline & ETtoday & http://www.ETtoday.net/ & ETtoday \\
\hline & Apple Daily & http://www.appledaily.com.tw/ & appledaily \\
\hline \multirow{5}{*}{ Shopping } & Ruten & http://www.ruten.com.tw/ & ruten \\
\hline & Taobao & http://taobao.com/ & taobao \\
\hline & Rakuten & http://www.rakuten.com.tw/ & rakuten \\
\hline & Pcstore & http://www.pcstore.com.tw/ & pcstore \\
\hline & Momoshop & http://www.momoshop.com.tw/ & momoshop \\
\hline \multirow{3}{*}{ Forum } & Ptt & http://www.ptt.cc/ & mo ptt \\
\hline & Mobile01 & http://www.mobile01.com/ & mobile01 \\
\hline & Gamer & http://www.gamer.com.tw/ & gamer \\
\hline \multirow{3}{*}{ Video } & Youtube & http://www.youtube.com/ & youtube \\
\hline & Youku & http://www.youku.com/ & youku \\
\hline & Funshion & http://www.fun.tv/ & fun \\
\hline
\end{tabular}




\begin{tabular}{|l|l|l|l|}
\hline \multirow{3}{*}{ Blog } & Pixnet & http://www.pixnet.net/ & pixnet \\
\cline { 2 - 4 } & Xuite & http://xuite.net/ & xuite \\
\hline
\end{tabular}

\section{Data Processing and Sample}

The purpose of web mining is to find valuable information from a large amount of information, so how to define the scope of web log files and make cleanup is a very important and complex task. In this study, the user's permission to install the App in the user's smartphone, and collect relevant data, including the date and time of user opening the App and browsing the web page. And return these data to the server for web usage mining. According to the web log file processing method reported by Cooley et al. (1999), this study used data cleaning, user identification, and session identification to preprocess the data, as follows:

\section{Data cleaning}

To ensure data quality, garbled text and entries with missing data points must be discarded. Table 2 shows the cleaned data. The field of Category records the category items set by this study; the field of Browsing records the user's application at that time.

Table 2. Meta Data Field

\section{\begin{tabular}{|l|l|l|l|l|l|}
\hline UserID & Date & Time & Category & App/Web & Browsing \\
\hline
\end{tabular}}

\section{Identification and sorting}

Because our data was recorded by user ID, user identification was simple. User identification proved helpful when sorting data. The data was organized by user ID and browsing date. An example is presented in Table 3.

Table 3. The Example After User Identification and Sorting

\begin{tabular}{|c|c|c|l|l|l|}
\hline UserID & Date & Time & Category & App/Web & \multicolumn{1}{|c|}{ Browsing } \\
\hline A & $2015 / 08 / 01$ & $07: 20: 29$ & sns & App & Facebook \\
\hline A & $2015 / 08 / 01$ & $13: 40: 28$ & forum & web & http://www.ptt.cc/ \\
\hline A & $2015 / 08 / 01$ & $13: 40: 33$ & news & web & http://www.ltn.com.tw/ \\
\hline
\end{tabular}

\section{Session identification}

A session refers to a series of interactions between two communication end points that occur during the span of a single connection. Session identification is simple when using sorted data. This study set a session limit of 15 minutes (900 seconds). When users' browsing time exceeds 15 minutes, the data is recorded as a new session. In this step, compared with the collected data, the session duration (unit: seconds) and ID (form: yyyymmdd+serial number) were recorded, as were the session dates and time stamps. Finally, whether the session was established using an application or a browser was recorded. The example is presented in Table 4. 
Table 4. The Example After Session Identification

\begin{tabular}{|c|c|c|c|c|c|c|c|}
\hline SessionID & $\begin{array}{c}\text { User } \\
\text { ID }\end{array}$ & Date & Time & Category & App/Web & Browsing & $\begin{array}{c}\text { Duration } \\
\text { (seconds) }\end{array}$ \\
\hline 201508011000001 & A & $2015 / 08 / 01$ & $15: 42: 50$ & sns & App & Facebook & 160 \\
\hline 201508011000001 & A & $2015 / 08 / 01$ & $15: 45: 30$ & forum & web & http://www.ptt.cc/ & 573 \\
\hline 201508011000002 & A & $2015 / 08 / 01$ & $18: 45: 30$ & news & web & http://www.ETtoday.net/ & 100 \\
\hline 201508011000003 & A & $2015 / 08 / 01$ & $20: 00: 10$ & sns & App & Facebook & 309 \\
\hline
\end{tabular}

After the three steps of data processing, we set a standard to select our sample. Users who browsed at least once monthly were deemed suitable for the study. We collected a total of 580 smartphone user samples as presented in Table 5.

Table5. The Sample Profile

\begin{tabular}{|c|l|l|c|}
\hline \multirow{4}{*}{$\begin{array}{c}\text { Data From } \\
2015 / 08 \\
\text { to }\end{array}$} & All unique visitors & 580 \\
\cline { 2 - 4 } $2015 / 10$ & \multirow{4}{*}{ Age } & Male & 284 \\
\cline { 3 - 4 } & & Female & 296 \\
\cline { 3 - 4 } & & 20 and below & 12 \\
\cline { 3 - 4 } & & 21 to30 & 194 \\
\cline { 3 - 4 } & & 31 to 40 & 243 \\
\cline { 3 - 4 } & & 41 and above & 131 \\
\hline
\end{tabular}

\section{RESULTS}

\section{Association Rules Calculations}

This study used Formulas 1 and 2 to measure the interestingness of rules discovered in each session. The rule form is P (SNS category's Site/App $\rightarrow$ other categories' Site/App). We set $1 \%$ as the minimum support and confidence. If the rule satisfied the minimum support and confidence, the lift of each rule was calculated. The lift's mean and the standard deviation were then stratified into three groups: high lift (mean $+1 / 2$ standard deviation; $x \geqq 2.87$ ), moderate lift (mean $\pm 1 / 2$ standard deviation; $1.86<\mathrm{x} \leqq 2.87$ ), and low lift (mean $-1 / 2$ standard deviation; $\mathrm{x} \leqq 1.86$ ).

The result shows in Table 6. The Facebook App has high lift degree with News (udnnews Web, ETtoday App/Web, Apple Daily Web), Forum (Ptt Web), Video (Youtube Web) and Blogs (Pixnet Web, Xuite App). Otherwise, Facebook Web has all moderate lift degree with News (udnnews Web, ETtoday App/Web, Apple Daily Web), Forum (Ptt App/Web), Video (Youtube Web) and Blogs (Pixnet Web, Xuite App). The results show that the Facebook Web usage might also important. 
Table 6. The association rules results of Facebook App/Web

\begin{tabular}{|c|c|c|c|c|c|c|}
\hline SNS & Categories & App/Web & $\begin{array}{c}\text { Minimum } \\
\text { support }\end{array}$ & $\begin{array}{c}\text { Minimum } \\
\text { Confidence }\end{array}$ & Lift & $\begin{array}{c}\text { Lift } \\
\text { degree }\end{array}$ \\
\hline \multirow{11}{*}{$\begin{array}{c}\text { Facebook } \\
\text { App }\end{array}$} & \multirow{4}{*}{ News } & udnnews Web & $1 \%$ & $4 \%$ & 3.21 & High \\
\hline & & ETtoday App & $1 \%$ & $2 \%$ & 3.33 & High \\
\hline & & ETtoday Web & $1 \%$ & $4 \%$ & 2.95 & High \\
\hline & & $\begin{array}{c}\text { Apple Daily } \\
\text { Web }\end{array}$ & $1 \%$ & $6 \%$ & 3.10 & High \\
\hline & \multirow{2}{*}{ Shopping } & Ruten App & $1 \%$ & $2 \%$ & 2.37 & Moderate \\
\hline & & Ruten Web & $1 \%$ & $2 \%$ & 2.11 & Moderate \\
\hline & \multirow{2}{*}{ Forum } & Ptt App & $1 \%$ & $5 \%$ & 1.71 & Low \\
\hline & & Ptt Web & $1 \%$ & $4 \%$ & 3.23 & High \\
\hline & Video & Youtube Web & $2 \%$ & $10 \%$ & 4.34 & High \\
\hline & \multirow{2}{*}{ Blogs } & Pixnet Web & $2 \%$ & $12 \%$ & 2.92 & High \\
\hline & & Xuite App & $1 \%$ & $3 \%$ & 2.92 & High \\
\hline \multirow{10}{*}{$\begin{array}{c}\text { Facebook } \\
\text { Web }\end{array}$} & \multirow{4}{*}{ News } & udnnews Web & $1 \%$ & $3 \%$ & 2.26 & Moderate \\
\hline & & ETtoday App & $1 \%$ & $2 \%$ & 2.44 & Moderate \\
\hline & & ETtoday Web & $1 \%$ & $3 \%$ & 2.47 & Moderate \\
\hline & & $\begin{array}{c}\text { Apple Daily } \\
\text { Web }\end{array}$ & $2 \%$ & $5 \%$ & 2.46 & Moderate \\
\hline & \multirow{2}{*}{ Forum } & Ptt App & $2 \%$ & $6 \%$ & 1.94 & Moderate \\
\hline & & Ptt Web & $1 \%$ & $3 \%$ & 2.36 & Moderate \\
\hline & Video & Youtube Web & $2 \%$ & $5 \%$ & 2.14 & Moderate \\
\hline & \multirow{3}{*}{ Blogs } & Pixnet Web & $3 \%$ & $9 \%$ & 2.15 & Moderate \\
\hline & & Xuite App & $1 \%$ & $2 \%$ & 2.42 & Moderate \\
\hline & & Xuite Web & $1 \%$ & $2 \%$ & 2.48 & Moderate \\
\hline
\end{tabular}

\section{Jaccard Index Calculations}

This study used Formula 4 to measure similarities in every session (showed in Appendix A). The degree of similarity was based on the mean and the standard deviation of Jaccard Index, which the calculation was the same as association rule. The three groups were: high similarities (mean $+1 / 2$ standard deviation; $x \geqq 0.03$ ), moderate similarities (mean $\pm 1 / 2$ standard deviation; $0.01<\mathrm{x} \leqq 0.03$ ), and low similarities (mean $-1 / 2$ standard deviation; $x \leqq 0.01$ ).

According to Jaccard Index, we analysis the similarity between App and the Web. The result shows in Table 7. We find that there are high similarities degree in News (ETtoday Web, Apple Daily Web), Forum (Ptt App/Web), Video (Youtube Web) and 
Blogs (Pixnet Web) between Facebook App and the Web. This result reveals that Facebook App/Web users may have the same information needs.

Table 7. The Jaccard Index results of Facebook App/Web Jaccard Index

\begin{tabular}{|c|c|c|c|c|}
\hline SNS & Categories & App/Web & Jaccard Index & Similarities degree \\
\hline \multirow{6}{*}{$\begin{array}{c}\text { Facebook } \\
\text { App }\end{array}$} & \multirow{2}{*}{ News } & ETtoday Web & 0.033 & High \\
\hline & & Apple Daily Web & 0.050 & High \\
\hline & \multirow{2}{*}{ Forum } & Ptt App & 0.061 & High \\
\hline & & Ptt Web & 0.031 & High \\
\hline & Video & Youtube Web & 0.047 & High \\
\hline & Blogs & Pixnet Web & 0.088 & High \\
\hline \multirow{7}{*}{$\begin{array}{c}\text { Facebook } \\
\text { Web }\end{array}$} & \multirow{3}{*}{ News } & udnnews Web & 0.036 & High \\
\hline & & ETtoday Web & 0.039 & High \\
\hline & & Apple Daily Web & 0.061 & High \\
\hline & \multirow{2}{*}{ Forum } & Ptt App & 0.050 & High \\
\hline & & Ptt Web & 0.042 & High \\
\hline & Video & Youtube Web & 0.095 & High \\
\hline & Blogs & Pixnet Web & 0.112 & High \\
\hline
\end{tabular}

\section{CONCLUSION}

We investigated smartphones users' SNS browsing patterns. Association rules and the Jaccard Index were used to determine the relationships between SNS and other variables. According to the Association rules, this study further explores the SNSrelated combinations that users visit in the same session (15 minutes). If users visit the App or Web of the same category in the same session, it is possible that the App or Web to be mutually competitive relationship. Examination of the association rules yielded two results. First, the lift degree of Facebook App is almost high, except Shopping (Ruten Web/App) and Forum (Ptt App) by contrast, the degree of lift of Facebook Web was moderate. Second, categories associated with Facebook were similar, although shopping had a negligible relationship with Facebook Web. The Jaccard Index revealed high-similarity relationships between Facebook and four categories (regardless of Web or App): news (ETtoday Web, Apple Daily Web), forums (Ptt App/Web), videos (Youtube Web), and blogs (Pixnet Web). Concluding this two finding, we can know that news, forums, videos, or blogs are people will browse together with Facebook in one session, then we can say that people have those information needs. 
The association rules and Jaccard Index yielded two findings. First, the categories of news and blogs were predominantly accessed through browsers, not Apps. Hence, users perhaps had differing informational needs with regard to news and blogs. We therefore suggest that developers integrate news and blog articles from their websites into the corresponding Facebook pages, thereby enhancing user experience by catering to a broader range of interests. Second, with high/middle lift degrees and high similarity degrees between Facebook Web/App and the selected categories, we infer that Taiwanese smartphone users use Facebook (both Web and App) as a news-seeking, topic-seeking, video-seeking and word-of-mouth-seeking platform. That means Facebook will become a portal. When people want to find something interesting, the first thing is to open Facebook and searching their timeline.

In the past, we can find that the research of network exploration with smart phones is rare. Most of them are investigated by questionnaire and focus on the research of information behavior in single target. In this study, we propose the Association rules and Jaccard Index to calculate the probability of occurrence between SNS App/Web and various categories App/Web. And we explain the meaning of users visit in the same session. However, this study provides insight into the behavior of mobile devices that will become the focus of future marketing. For each App / Web marketer, they can know the probability of each category and the SNS appearing at the same time in a short time. For example: the category of news and Facebook App associated with higher. For the SNS operators, they can enhance the convenience of users to switch between categories. By knowing the probability of each category and the SNS appearing at the same time in a short time, we can understand how the information between App / Web in each category should be selected for streaming. For example: we can stream Facebook and the category of news (ETtoday Web, Apple Daily Web) messages to help users browse news from different sources at the same time.

This study has certain limitations. Through web usage mining, we could only analyze how users seek and navigate information. However, combining the data with interviews or questionnaires may provide insight into user motivation and what types of information are important to the users. Because the categories and Web/App were determined using InsightXplorer data, the study scale offeres limited diversity. Additional categories would broaden the scope of the study and provide more detailed information. In addition, this study examines the relationship between SNS and other categories. In future research, the user's profile and time can be further explored. For example, when people browse news and Facebook (weekdays or weekend, 24 hours in one day) or which age or gender prefer browse Facebook and Forum. With more exploring, users' information behavior will be more interesting. 


\section{REFERENCES}

Agrawal, R., \& Srikant, R. (1994). Fast algorithms for mining association rules. In B.B. Jorge, J. Matthias, \& Z. Carlo (Eds.), Proceeding of 20th International Conference on Very Large Data Bases, 1(1215), 487-499. San Francisco, CA, USA: Morgan Kaufmann.

Bates, M. (2010). Information behavior. In Macia J. B. \& Mary N. M. (Eds.), Encyclopedia of Library and Information Sciences., 3, 2381-2391. New York: CPC Press.

Berry, M.J., and Linoff, G. (1997). Data mining techniques: For marketing, sales, and customer support. New York, USA: John Wiley \& Sons.

Broder, A. (2002). A taxonomy of web search. In ACM Sigir forum, 36(2)3-10. https://doi.org/10.1145/792550.792552

Bronto (2015), Consumers Tell All: What is the device of choice for online shoppers?, Retrieved from : http://bizibl.com/marketing/download/consumers-tell-all-whatdevice-choice-online-shoppers

Bucklin, R. E., \& Sismeiro, C. (2009). Click here for internet insight: Advances in clickstream data analysis in marketing. Journal of Interactive Marketing, 23(1), 35-48. https://doi.org/10.1016/j.intmar.2008.10.004

Chen, Y. M., Hsu, T. H., \& Lu, Y. J. (2018). Impact of flow on mobile shopping intention. Journal of Retailing and Consumer Services, 41, 281-287. https://doi.org/10.1016/j.jretconser.2017.04.004

Chou, P. H., Li, P. H., Chen, K. K., \& Wu, M. J. (2010). Integrating web mining and neural network for personalized e-commerce automatic service. Expert Systems with Applications, 37(4), 2898-2910. https://doi.org/10.1016/j.eswa.2009.09.047

Church, K., \& Smyth, B. (2009). Understanding the intent behind mobile information needs. In J. Sullivan \& S. Tyler, (Eds), Proceedings of the 14th International Conference on Intelligent User Interfaces. 247-256. FL, USA: Sanibel Island.

Cooley, R., Mobasher, B., \& Srivastava, J. (1997). Web mining: Information and pattern discovery on the world wide web. In the Proceedings of the 9th IEEE International Conference on Tools with Artificial Intelligence, 558-567. https://doi.org/10.1109/tai.1997.632303

Cooley, R., Mobasher, B., \& Srivastava, J. (1999). Data preparation for mining world wide web browsing patterns. Knowledge and Information Systems, 1(1), 5-32. https://doi.org/10.1007/bf03325089

Cui, Y., \& Roto, V. (2008). How people use the web on mobile devices. Proceedings of the 17th International Conference on World Wide Web, 905-914. New York, USA: Associate for Computing Machinery. https://doi.org/10.1145/1367497.1367619 
Etzioni, O. (1996). The World-Wide Web: Quagmire or gold mine?. Communications of the ACM, 39(11), 65-68. https://doi.org/10.1145/240455.240473

Foreseeing Innovative New Digiservices (2015). The Plan of Services Experience and Design Innovation Research (3/4). Retrieved from :

http://www.find.org.tw/market_info.aspx?n_ID=8482

Garton, L., Haythornthwaite, C., \& Wellman, B. (1997). Studying online social networks. Journal of computer-mediated communication, 3(1), JCMC313. https://www.learntechlib.org/p/83989/

Google \& Ipsos MediaCT, Our Mobile Planet: Taiwan, Understanding the mobile consumer. Retrieved from : https://www.thinkwithgoogle.com/mobileplanet/zhtw/

Ha, Y. W., Kim, J., Libaque-Saenz, C. F., Chang, Y., \& Park, M. C. (2015). Use and gratifications of mobile SNSs: Facebook and KakaoTalk in Korea.Telematics and Informatics, 32(3), 425-438. https://doi.org/10.1016/j.tele.2014.10.006

Halvey, M., Keane, M.T., \& Smyth B. (2006). Time based patterns in mobile-internet surfing. Proceedings of the SIGCHI Conference on Human Factors in Computing Systems of CHI'06, 31-34. New York, USA: ACM. https://doi.org/10.1145/1124772.1124778

Huberman, B. A., Pirolli, P. L., Pitkow, J. E., \& Lukose, R. M. (1998). Strong regularities in world wide web surfing. Science, 280(5360), 95-97. https://doi.org/10.1126/science.280.5360.95

Ito, M., Okabe, D., \& Matsuda, M. (Eds.). (2005). Personal, Portable, Pedestrian: Mobile Phones in Japanese Life. Cambridge, MA: MIT Press.

Jones, M., Buchanan, G., Cheng, T.C., \& Jain, P. (2006). Changing the pace of search: Supporting "background” information seeking. Journal of the American Society for Information Science and Technology, 57(6), 838-842. https://doi.org/10.1002/asi.20304

Kwon, O., \& Wen, Y. (2010). An empirical study of the factors affecting social network service use. Computers in human behavior, 26(2), 254-263. https://doi.org/10.1016/j.chb.2009.04.011

Katz, J. E., Katz, J. E., \& Aakhus, M. (Eds.). (2002). Perpetual contact: Mobile communication, private talk, public performance. Cambridge University Press. https://reurl.cc/7DkXN

Knight Foundation (2015), News goes mobile: How people use smartphones to access information. Retrieved June 20, 2016 from : https://medium.com/mobile-firstnews-how-people-use-smartphones-to/news-goes-mobile-how-people-usesmartphones-to-access-information-53ccb850d80a\#.14cf9bkph 
Kosala, R., \& Blockeel, H. (2000). Web mining research: A survey. ACM SIGKDD Explorations Newsletter, 2(1), 1-15. https://doi.org/10.1145/360402.360406

Ling, R. (2004). The mobile connection: The cell phone's impact on society. Elsevier. https://goo.gl/96gDh4

Looney, C., Jessup, L. and Valacich, J. (2004). Emerging business models for mobile brokerage services. Communications of the ACM, 47(6), 71-77.

https://doi.org/10.1145/990680.990683

Nikou, S., Bouwman, H., \& de Reuver, M. (2014). A consumer perspective on mobile service platforms: A conjoint analysis approach. CAIS, 34, 82.

https://doi.org/10.17705/1cais.03482

Nicholas, D., Clark, D., Rowlands, I., \& Jamali, H. R. (2013). Information on the go: A case study of Europeana mobile users. Journal of the American Society for Information Science and Technology, 64(7), 1311-1322.

https://doi.org/10.1002/asi.22838

Pettigrew, K. E., Fidel, R., and Bruce, H. (2001). Conceptual frameworks in information behavior. Annual Review of Information Science and Technology, 35, 43-78.

Raacke, J., \& Bonds-Raacke, J. (2008). MySpace and Facebook: Applying the uses and gratifications theory to exploring friend-networking sites. Cyberpsychology \& behavior, 11(2), 169-174. https://doi.org/10.1089/cpb.2007.0056

Rioux, K. S. (2005). Information acquiring-and-sharing. In Fisher, K. E., Erdelez, S., \& McKechnie, L. (Eds.). Theories of information behavior, Information Today, Inc., 169-172.

Sellen, A. J., Murphy, R., \& Shaw, K. L. (2002). How knowledge workers use the Web. Proceedings of the SIGCHI Conference on Human Factors in Computing Systems, 227-234. Minneapolis, New York: ACM Press.

https://doi.org/10.1145/503417.503418

Wilson, T. D. (1999). Models in information behaviour research. Journal of Documentation, 55(3), 249-270. https://doi.org/10.1108/eum0000000007145

Wilson, T. D. (2000). Human information behavior. Informing Science, 3(2), 49-56. https://doi.org/10.28945/576

Zhou, T., Li, H., \& Liu, Y. (2010). The effect of flow experience on mobile SNS users' loyalty. Industrial Management \& Data Systems, 110(6), 930-946. https://doi.org/10.1108/02635571011055126

Dr. I-Ping Chiang (Corresponding author) is currently professor of Graduate Institute of Information Management, National Taipei University. His current research interests include Business Administration, Marketing, Finance, Consumer Behavior. He also published many articles on IJECS, SSI. 
Ms. Jie-Yun Yang graduated from Graduate Institute of Information Management, National Taipei University.

Ms. Yi-Jou Wu is studying at Graduated from Graduate Institute of Information Management, National Taipei University.

\section{APPENDIX A}

Table1. SNS and Various Category of Jaccard Index

\begin{tabular}{|c|c|c|c|c|}
\hline \multicolumn{3}{|c|}{ Jaccard Index } & \multicolumn{2}{|c|}{ Facebook } \\
\hline Categories & Sites name & App/Web & App & Web \\
\hline \multirow{10}{*}{ News } & \multirow{2}{*}{ China Times } & App & 0.001 & 0.001 \\
\hline & & Web & 0.008 & 0.011 \\
\hline & \multirow{2}{*}{$\begin{array}{c}\text { Liberty } \\
\text { Times Net }\end{array}$} & App & 0.004 & 0.004 \\
\hline & & Web & 0.011 & 0.010 \\
\hline & \multirow{2}{*}{ udnnews } & App & 0.005 & 0.007 \\
\hline & & Web & 0.026 & 0.036 \\
\hline & \multirow{2}{*}{ ETtoday } & App & 0.018 & 0.025 \\
\hline & & Web & 0.033 & 0.039 \\
\hline & \multirow{2}{*}{ Apple Daily } & App & 0.012 & 0.017 \\
\hline & & Web & 0.050 & 0.061 \\
\hline \multirow{10}{*}{ Shopping } & \multirow{2}{*}{ Ruten } & App & 0.018 & 0.017 \\
\hline & & Web & 0.022 & 0.018 \\
\hline & \multirow{2}{*}{ Taobao } & App & 0.004 & 0.005 \\
\hline & & Web & 0.008 & 0.011 \\
\hline & \multirow{2}{*}{ Rakuten } & App & 0.008 & 0.008 \\
\hline & & Web & 0.013 & 0.012 \\
\hline & \multirow{2}{*}{ Pcstore } & App & 0.001 & 0.001 \\
\hline & & Web & 0.005 & 0.007 \\
\hline & \multirow{2}{*}{ Momoshop } & App & 0.000 & 0.000 \\
\hline & & Web & 0.012 & 0.020 \\
\hline \multirow{6}{*}{ Forum } & \multirow{2}{*}{ Ptt } & App & 0.061 & 0.050 \\
\hline & & Web & 0.031 & 0.042 \\
\hline & \multirow{2}{*}{ Mobile01 } & App & 0.006 & 0.005 \\
\hline & & Web & 0.012 & 0.012 \\
\hline & \multirow{2}{*}{ Gamer } & App & 0.000 & 0.001 \\
\hline & & Web & 0.009 & 0.021 \\
\hline Video & Youtube & App & 0.006 & 0.010 \\
\hline
\end{tabular}




\begin{tabular}{|c|c|c|c|c|}
\hline \multicolumn{3}{|c|}{ Jaccard Index } & \multicolumn{2}{|c|}{ Facebook } \\
\hline Categories & Sites name & App/Web & App & Web \\
\hline & & Web & 0.047 & 0.095 \\
\hline & \multirow{2}{*}{ Youku } & App & 0.001 & 0.001 \\
\hline & & Web & 0.001 & 0.002 \\
\hline & \multirow{2}{*}{ Funshion } & App & 0.000 & 0.001 \\
\hline & & Web & 0.001 & 0.001 \\
\hline \multirow{4}{*}{ Blog } & \multirow{2}{*}{ Pixnet } & App & 0.002 & 0.004 \\
\hline & & Web & 0.088 & 0.112 \\
\hline & \multirow{2}{*}{ Xuite } & App & 0.022 & 0.026 \\
\hline & & Web & 0.019 & 0.022 \\
\hline
\end{tabular}

